gender $(69.2 \%$ vs. $54.3 \%$; $p=0.02)$, condition of "current smoker" $(22.1 \%$ vs. $10.9 \%$; $p=0.012$ ), ESR [median (IQR): 30.0 (19.0-48.0) vs. 40.0 (2562); $\mathrm{p}=0.035$ ] and DAS28 (mean \pm standard deviation: $5.5 \pm 1.1$ vs. 5.2 $\pm 1.3 ; \mathrm{p}=0.037)$. High-titre positivity for RF and/or ACPA $(57.3 \%$ vs. $45.9 \% ; p=0.095)$ and high cumulative steroids dose [852 mg (300-1200) vs. $691 \mathrm{mg}$ (0-150); $\mathrm{p}=0.071$ ] were numerically higher in IR.

In multivariate analysis, the "current smoker" condition was confirmed as the only independent factor associated with IR to MTX after 6 months of treatment (OR: 2.333, 95\% Cl: 1.132-4.805; $\mathrm{p}=0.022$ ).

No significant association between ex-smoker status and IR to MTX was demonstrated. This result was confirmed even after stratification of exsmokers over the time since smoking stop. Finally, for both current smokers and ex-smokers, the duration of exposure to cigarette smoking did not show any significant association with IR.

Conclusion: In this RA cohort, the condition of "current smoker" was the only predictor of IR to MTX. This observation, together with the lack of association between previous smoking habit and IR to MTX, further prompt to recommend cessation of cigarette smoking in patients with RA who begin treatment with MTX.

Table 1. Baseline demographic, clinical and serological features.

\begin{tabular}{|c|c|}
\hline Gender, n (\%) Female & $142(60.9 \%)$ \\
\hline Age at enrollment, mean $( \pm S D)$, yrs & $54.2( \pm 14.5)$ \\
\hline RF/ACPA positivity, n (\%) & $132(60.5 \%)$ \\
\hline $\mathrm{BMI}$, mean $( \pm \mathrm{SD}) \mathrm{Kg} / \mathrm{m}^{2}$ & $24.9( \pm 4.1)$ \\
\hline Current smoker, n (\%) & $37(15.9 \%)$ \\
\hline Ex smoker, n (\%) & $89(38.2 \%)$ \\
\hline DAS28, mean $( \pm$ SD) & $5.3( \pm 1.2)$ \\
\hline TJC28, median (IQR) & $9(5-15)$ \\
\hline SJC28, median (IQR) & $5(2-10)$ \\
\hline $\mathrm{ESR}$, mean $( \pm \mathrm{SD})$ & $39.9( \pm 24.9)$ \\
\hline X-ray Erosion, n (\%) & $36(22.3 \%)$ \\
\hline Rheumatoid Nodules, n (\%) & $8(3.4 \%)$ \\
\hline
\end{tabular}

DS: standard deviation; RF: factor rheumatoid factor; ACPA: anti-citrullinated peptide antibodies; BMI: body mass index; DAS-28: disease activity score; TJC: tender joint count; SJC: swollen joint count; ESR: erythrocytes sedimentation rate.

Acknowledgement: This study was supported by an unconditioned Research grant from Pfizer Inc.

Disclosure of Interests: None declared

DOI: 10.1136/annrheumdis-2019-eular.7734

\section{THU0096 PERSISTENT HIGH DISEASE ACTIVITY IN THE ANTI- CARBAMYLATED PROTEIN ANTIBODY POSITIVE EARLY ARTHRITIS PATIENTS INDEPENDENTLY OF TREATMENT}

Cristina Regueiro ${ }^{1}$, Ana Ortiz ${ }^{2}$, Laura Nuño ${ }^{3}$, Diana Peiteado ${ }^{3}$, Alejandro Villalva ${ }^{3}$, Dora Pascual Salcedo ${ }^{3}$, Ana Martínez-Feito ${ }^{3}$, Alejandro Balsa ${ }^{3}$, Isidoro GonzálezÁlvaro ${ }^{2}$, Antonio Gonzalez ${ }^{1}{ }^{1}$ Insituto de Investigacion Sanitaria - Hospital Clinico Universitario de Santiago, Santiago de Compostela, Spain; ${ }^{2}$ Insituto de Investigacion Sanitaria del Hospital de La Princesa (IIS-IP), Madrid, Spain; ${ }^{3}$ Insituto de Investigacion del Hospital Universitario La Paz (IdiPAZ), Madrid, Spain

Background: There is great interest in the identification of prognostic biomarkers informing early therapeutic decisions for the improvement of rheumatoid arthritis (RA) evolution. Promising results in early arthritis (EA) patients indicate the anti-carbamylated protein antibodies (ACarPA) may serve this function. In effect, they are associated with high baseline disease activity and, in our patients, with less improvement in the first 6months of follow-up. This association was independent of sex, age at diagnosis, time since symptoms onset, smoking and the year of onset. However, the influence of the treatment has not been explored yet.

Objectives: We aimed to explore the influence of the initial treatment on the persistent high disease activity associated with the presence of ACarPA in EA patients.

Methods: Samples were obtained at the first visit of two EA cohorts from Hospital Universitario La Paz and Hospital Universitario La Princesa, which recruit patients within one year from the clinical onset. Information on the initial treatment and the disease activity at the baseline and at 6months of follow-up was available from 546 patients. Treatment was categorized according to the use of corticosteroids, methotrexate (MTX) and other DMARDs, and considering changes in the first 6 months. In addition, MTX dose was considered either quantitatively or as a dichotomous variable $(\geq 12.5 \mathrm{mg}$ and $<12.5 \mathrm{mg}$ ). Main effects general linear regression was used for analysis, including the treatment and the other confounders as covariates.

Results: A large fraction (83\%) of the EA patients received specific treatment from the initial visit. It comprised DMARD (50.1\%), corticosteroids $(10.6 \%)$, or a combination of both $(39.3 \%)$. The most common DMARD was MTX (82.2\%), whereas less frequently used medications included sulfasalazine $(5.4 \%)$, leflunomide $(3.2 \%)$, hydroxychloroquine $(8.1 \%)$ and other $(1.0 \%)$. The $35.5 \%$ of the treated patients maintained the treatment during the 6-month follow-up. The presence of ACarPA was associated with a 0.45 higher mean baseline DAS28 and with less decrease of DAS28 ( $\triangle \mathrm{DAS} 28$ ) from the baseline to 6 months of follow-up $(\beta=0.08$ $\mathrm{p}=0.016)$, as already communicated. This latter association persisted without modification after accounting for the initial treatment (DMARD, corticosteroids, and changes in treatment). In addition, it was independent of the consideration of all DMARDs in a single group, or separated into two categories: MTX and the other. Similarly, the association was independent on MTX dose, defined both as a categorical or a quantitative variable. Conclusion: The association of ACarPA with a persistently increased disease activity in EA patients is independent of the initial treatment. These results reinforce the possibility that ACarPA can be useful as prognostic biomarkers for the first 6 months of evolution and indicate the need for personalized management of the patients carrying ACarPA.

Acknowledgement: Supported by grants PI17/01606 and RD16/0012/0014 of the Instituto de Salud Carlos III (Spain) that are partially financed by FEDER.

Disclosure of Interests: Cristina Regueiro : None declared, Ana Ortiz: None declared, Laura Nuño: None declared, Diana Peiteado: None declared, Alejandro Villalva: None declared, Dora Pascual Salcedo: None declared, ANA MARTÍNEZ-FEITO: None declared, Alejandro Balsa Grant/ research support from: Abbvie, Pfizer, Novartis, BMS, Nordic, Sanofi, Consultant for: Abbvie, Pfizer, Novartis, BMS, Nordic, Sanofi, Sandoz, Lilly, Paid instructor for: Pfizer, Speakers bureau: Pfizer, Novartis, UCB, Nordic, Sanofi, Sandoz, Lilly, Isidoro González-Álvaro: None declared, Antonio Gonzalez: None declared

DOI: 10.1136/annrheumdis-2019-eular.4696

\section{\begin{tabular}{l|l} 
THU0097 & VALUEOF ANTIBODIES AGAINST ACETYLATED
\end{tabular} PEPTIDES FOR THE CLASSIFICATION OF PATIENTS WITH EARLY ARTHRITIS}

Lorena Rodríguez-Martínez ${ }^{1}$, Holger Bang ${ }^{2}$, Laura Nuño ${ }^{3}$, Diana Peiteado ${ }^{3}$, Ana Ortiz ${ }^{4}$, Alejandro Villalva ${ }^{3}$, Dora Pascual-Salcedo ${ }^{3}$, Ana Martínez-Feito ${ }^{3}$, Alejandro Balsa ${ }^{3}$, Isidoro González-Álvaro ${ }^{4}$, Antonio Gonzalez ${ }^{1}{ }^{1}$ Instituto de Investigación Sanitaria-Hospital Clínico Universitario de Santiago, Experimental and Observational Rheumatology, Santiago de Compostela, Spain; ${ }^{2}$ Orgentec Diagnostika GmbH, Mainz, Germany, ${ }^{3}$ Instituto de Investigacion del Hospital de La Paz (IDIPAZ), Madrid, Spain; ${ }^{4}$ Instituto de Investigación del Hospital de La Princesa (IIS-IP), Madrid, Spain

Background: Patients with rheumatoid arthritis (RA) achieve the best response when they receive adequate treatment as soon as possible. This fact motivated the modification of the classification criteria by the ACR and the EULAR in 2010 to enable early detection. One of the changes is the increased weight conferred to the autoantibodies: rheumatoid factor and anti-citrullinated protein antibodies. As these antibodies are not present in all patients, other antibodies could provide similar information. In this regard, the antibodies that recognize an acetylated peptide from mutated vimentin (Anti-Acetylated Peptide Antibodies or AAPA) stand out (1)

Objectives: We aimed to evaluate the AAPA predictive value at the baseline visit for the classification of early arthritis patients.

Methods: A total of 438 patients with available samples and information were randomly selected from two early arthritis clinics. The AAPA were determined in baseline sera as previously described (1). Two peptides were included, one acetylated at a lysine (anti-AcLys) and the other at an ornithine (anti-AcOrn) and considered either individually or combined. The sensitivity, specificity, predictive positive (PPV) and negative (PNV) values and the AUC of the ROC curve were assessed. Logistic regression was also applied adjusting for age, sex, the centre of origin, antiCCP, and RF. The study was approved by the ethics committee of the Hospital Universitario La Paz, the Hospital Universitario La Princesa, and Autonómico de Galicia.

Results: The AAPA at baseline were sensitive and specific for the classification of the patients fulfilling RA criteria (46.8\%) at the end of the 2-year follow-up (table 1). Specifically, the anti-AcOrn antibodies were slightly 
more sensitive and specific than the anti-AcLys ones. The two and their combination showed a conserved specificity for the seronegative patients, but a lower sensitivity than for the seropositive ones. Consequently, the PPV for the seronegative patients was low, although the NPV was high. In the same vein, the AUC was insufficient for the seronegative patients. The regression analysis including the anti-CCP and RF revealed a significant contribution of the anti-AcOrn antibodies $(\mathrm{OR}=2.1,95 \% \mathrm{Cl}=1.1-$ 4.0, $\mathrm{P}=0.02$ ), but not of the anti-AcLys antibodies. On the other hand, the inclusion of the AAPA in the classification resulted in an increase in sensitivity of $5.4 \%$ at the cost of a $13.7 \%$ lower specificity, which is an improvement over the anti-carbamylated protein antibodies.

Abstract THU0097 - Table 1. Parameters assessing the diagnostic value of the antiacetylated peptide antibodies taken individually and in combination for the classification of the RA patients or the indicated patient subsets subset.

\begin{tabular}{|c|c|c|c|}
\hline & anti-Aslys & anti-Asclocu & AAPA \\
\hline \multicolumn{4}{|l|}{ Sensitivity } \\
\hline all & 37.9 & 44.2 & 50.5 \\
\hline anti-CCP- & 16.9 & 16.9 & 22.5 \\
\hline anti-CCP-\& RF- & 15.7 & 15.7 & 21.6 \\
\hline \multicolumn{4}{|l|}{ Specificity } \\
\hline all & 84.5 & 86.6 & 81.0 \\
\hline anti-CCP- & 87.4 & 87.9 & 83.8 \\
\hline anti-CCP-\& RF- & 86.8 & 86.8 & 82.8 \\
\hline \multicolumn{4}{|l|}{ PPV } \\
\hline all & 68.4 & 74.6 & 70.3 \\
\hline anti-CCP- & 32.4 & 33.3 & 33.3 \\
\hline anti-CCP-\& RF- & 25.8 & 25.8 & 26.8 \\
\hline \multicolumn{4}{|l|}{ NPV } \\
\hline all & 60.5 & 63.6 & 64.8 \\
\hline anti-CCP- & 74.6 & 74.7 & 75.1 \\
\hline anti-CCP- \& RF- & 77.8 & 77.8 & 78.3 \\
\hline \multicolumn{4}{|l|}{ AUC } \\
\hline all & 0.61 & 0.65 & 0.66 \\
\hline anti-CCP- & 0.52 & 0.52 & 0.53 \\
\hline anti-CCP- \& RF- & 0.51 & 0.51 & 0.52 \\
\hline
\end{tabular}

Supported by grants PI17/01606 and RD16/0012/0014 of the Instituto de Salud Carlos III (Spain) that are partially financed by the FEDER

Conclusion: The AAPA show high specificity and sensitivity for RA in early arthritis patients. However, their contribution to RA classification is minor once RF and the anti-CCP antibodies have been considered. But nevertheless, AAPA supports the drive to close the diagnostic gap in this early disease phase and to increase the likelihood of successful therapy.

\section{REFERENCES:}

[1] Juarez, M, et al. Ann Rheum Dis. 2016; 75:1099-1107

Disclosure of Interests: Lorena Rodríguez-Martínez: None declared, Holger Bang Employee of: Dr. Bang is employee of the diagnostic company Orgentec Diagnostika., Laura Nuño: None declared, Diana Peiteado: None declared, Ana Ortiz: None declared, Alejandro Villalva: None declared, DORA PASCUAL-SALCEDO Grant/research support from: Pfizer, Speakers bureau: Pfizer, Abbvie, Takeda, ANA MARTÍNEZ-FEITO: None declared, Alejandro Balsa Grant/research support from: Abbvie, Pfizer, Novartis, BMS, Nordic, Sanofi, Consultant for: Abbvie, Pfizer, Novartis, BMS, Nordic, Sanofi, Sandoz, Lilly, Paid instructor for: Pfizer, Speakers bureau: Pfizer, Novartis, UCB, Nordic, Sanofi, Sandoz, Lilly, Isidoro GonzálezÁlvaro: None declared, Antonio Gonzalez: None declared DOI: 10.1136/annrheumdis-2019-eular.5754

\section{THU0098 WHICH FACTORS INFLUENCE ACHIEVEMENT OF TREATMENT SATISFACTION IN RHEUMATOID ARTHRITIS?}

Martin Schaefer ${ }^{1}$, Jörn Kekow ${ }^{2}$, Karin Rockwitz ${ }^{3}$, Anke Liebhaber ${ }^{4}$, Angela Zink ${ }^{1}$, Anja Strangfeld ${ }^{1} .{ }^{1}$ German Rheumatism Research Center, Berlin, Germany; ${ }^{2}$ Scientific Advisory Board, Vogelsang-Gommern, Germany; ${ }^{3}$ Rheumatologist, Goslar, Germany, ${ }^{4}$ Rheumatologist, Halle/Saale, Germany

Background: The satisfaction of RA patients with their pharmacological therapy is a relevant patient reported outcome which influences treatment adherence and continuation. However, it has not been investigated frequently, and almost never in large studies.

Objectives: To assess factors exerting a potential influence on the satis faction with the pharmacological treatment and to quantify this influence.

Methods: The German register RABBIT is a prospective longitudinally followed cohort of RA patients enrolled with a new start of a DMARD after at least one csDMARD failure. This analysis comprises patients who were enrolled with start of a DMARD between 01/2009 and 04/2018, who were observed for at least 12 months and had been on the therapy prescribed at enrolment for at least six months.

Abstract THU0098 -Table 1

Table 1: Results of logistic regression to analyze potential factors influencing satisfaction with drug treatment

\begin{tabular}{|c|c|c|}
\hline Parameter & Odds Ratio & $95 \%$ confidence limits \\
\hline Satisfied at treatment start & 3.11 & $(2.61 ; 3.70)$ \\
\hline DAS28 reduction (one unit) after one year & 1.34 & $(1.26 ; 1.41)$ \\
\hline Reduction (one unit on a scale of 1-10) of pain after one year & 1.28 & $(1.23 ; 1.32)$ \\
\hline Reduction of sleeping problems (one unit on a scale of 1-10) & 1.01 & $(0.99 ; 1.04)$ \\
\hline Reduction of fatigue (one unit on a scale of 1-10) & 1.00 & $(0.97 ; 1.03)$ \\
\hline Improvement of physical function by 10 percentage points & & \\
\hline of full capacity & 1.19 & $(1.13 ; 1.26)$ \\
\hline Prior biologic therapy & 0.80 & $(0.67 ; 0.96)$ \\
\hline Reduction of glucocorticoid dose $(\text { one } \log (\mathrm{mg}) / \mathrm{d})^{*}$ & 1.37 & $(1.18 ; 1.59)$ \\
\hline Congestive heart failure & 1.08 & $(0.62 ; 1.90)$ \\
\hline Diabetes & 0.98 & $(0.77 ; 1.25)$ \\
\hline Chronic kidney disease & 0.96 & $(0.66 ; 1.38)$ \\
\hline Prior malignancies & 1.08 & $(0.74 ; 1.57)$ \\
\hline Degenerative spine disease & 0.93 & $(0.75 ; 1.14)$ \\
\hline Degenerative joint disease & 0.93 & $(0.75 ; 1.14)$ \\
\hline Osteoporosis & 0.86 & $(0.68 ; 1.07)$ \\
\hline Fibromyalgia & 0.75 & $(0.50 ; 1.13)$ \\
\hline Depression & 0.65 & $(0.50 ; 0.86)$ \\
\hline Obesity & 0.82 & $(0.69 ; 0.96)$ \\
\hline Age at disease onset (years) & 1.00 & $(0.996 ; 1.01)$ \\
\hline Women (reference: $\mathrm{men}$ ) & 1.04 & $(0.87 ; 1.24)$ \\
\hline Seropositivity (RF/ACPA) & 1.13 & $(0.97 ; 1.32)$ \\
\hline Ever smoked & 0.89 & $(0.76 ; 1.04)$ \\
\hline Smoking habits unknown & 1.09 & $(0.74 ; 1.62)$ \\
\hline Biologic therapy (reference: csDMARDs) & 1.07 & $(0.90 ; 1.28)$ \\
\hline
\end{tabular}

logarithmically transformed glucocorticoid dose was used in the model.

Satisfaction with the applied treatment was measured in four categories from "very satisfied" to "very unsatisfied". Logistic regression combined with multiple imputation of missing values was performed to calculate odds ratios (ORs) for factors which might have an influence on treatment satisfaction.

Results: At treatment onset, $55 \%$ of the 8,177 patients were "very" or "rather" satisfied (in the following: "satisfied"), while the rest was "very" or "rather" unsatisfied (in the following: "unsatisfied") with their therapy. After one year of treatment, $86 \%$ of patients were satisfied with their treatment. Factors with positive impact on whether patients reached the target of treatment satisfaction were satisfaction at baseline, reduction of DAS28BSG, pain and glucocorticoid dose as well as the increase of physical function. Depression, obesity as well as a prior treatment failure of bDMARDs had a negative influence on the outcome (see Table 1). The DAS28 component most influential on treatment satisfaction was the patient global health assessment. Regarding glucocorticoid therapy, being still treated with either 5 to $15 \mathrm{mg}$ (OR: $0.66,95 \% \mathrm{Cl}: 0.55 ; 0.79$ ) or $\geq$ $15 \mathrm{mg}$ glucocorticoids (OR: $0.25,95 \% \mathrm{Cl}: 0.15 ; 0.41$ ) had a negative impact on the achievement of therapy satisfaction (data not shown).

Conclusion: Reductions in disease activity, pain and glucocorticoid dosage as well as improvement of physical function increase the chance to achieve treatment satisfaction. On the other hand, depression and obesity as well as prior treatment failures with bDMARDs are obstacles to therapy satisfaction. For physicians, these results suggest that efforts to taper glucocorticoid doses are worthwhile to improve patient's satisfaction.

Acknowledgement: Disclosure: RABBIT is supported by a joint, unconditional grant from AbbVie, Bristol-Myers Squibb, Celltrion, Hexal, Lilly, MSD Sharp \& Dohme, Pfizer, Roche, Samsung Bioepis, Sanofi-Aventis, and UCB. Disclosure of Interests: Martin Schaefer: None declared, Jörn Kekow: None declared, Karin Rockwitz: None declared, Anke Liebhaber: None 